\title{
Comparative Biochemistry of the Cell Envelopes of Photobacterium leiognathi and Escherichia coli
}

\author{
By G. K. SCOTT,$^{*} \mathrm{~K} . \mathrm{SMITH}^{2} \dagger$ AND C. M. THOREAU ${ }^{1}$ \\ ${ }^{1}$ Department of Biochemistry, University of Auckland, Auckland, New Zealand, \\ ${ }^{2}$ Department of Biochemistry, Massey University, Palmerston North, New Zealand
}

(Received 28 September 1982)

\begin{abstract}
Photobacterium leiognathi closely resembles Escherichia coli with respect to cell lysis by lysozyme, and the fractionation of outer and cytoplasmic membranes. The two organisms differ in their phospholipid contents and, more significantly, in outer membrane protein compositions.
\end{abstract}

\section{INTRODUCTION}

Photobacterium leiognathi ( $P$. mandapamensis) is a luminescent marine bacterium found as the specific symbiont in the luminous organ of Leiognathid and Apogonid fish, as a marine intestinal commensal or free-living in sea water (Reichelt \& Baumann, 1973; Nealson \& Hastings, 1979). The genus shares many properties with the Enterobacteriaceae (Baumann \& Baumann, 1977). In particular, electron microscopy of thin sections of this organism reveals a cell envelope which is morphologically very similar to terrestrial Gram-negative bacteria, with the characteristic membrane, cell wall, periplasmic space and outer membrane (Reichelt \& Baumann, 1973). It would not be surprising if closer analysis of the cell envelope of $P$. leiognathi revealed considerable differences from typical Gram-negative bacteria, since the marine organism must cope with a constant high osmotic pressure. At the same time, there is some evidence for greater membrane permeability in this genus. We have observed that $P$. leiognathi has a relatively high sensitivity to a variety of antibiotics and chemical mutagens. In addition, the periplasmic $\beta$-lactamase of Photobacterium species does not generally display the 'crypticity' typical of this enzyme in most other Gram-negative bacteria (Richmond and Sykes, 1973), and usually taken as a measure of outer membrane impermeability to $\beta$-lactam antibiotics (K. Smith $\&$ S. Lamb, unpublished results). We have accordingly analysed various aspects of the biochemistry of the cell envelope of $P$. leiognathi with particular emphasis on the composition of the outer membrane, and using Escherichia coli for comparative purposes.

\section{METHODS}

Growth of bacteria. The maintenance and growth of Escherichia coli ML308 225 have been described previously (Allen \& Scott, 1979). Photobacterium leiognathi strain K-721 (Nealson \& Hastings, 1977) was obtained from the Roche Research Institute of Marine Pharmacology in Sydney, and was grown in liquid cultures using minimal medium (Reichelt \& Baumann, 1973) without $\mathrm{CaCl}_{2}$ and supplemented with $0 \cdot 2 \%(\mathrm{w} / \mathrm{v})$ yeast extract. This bacterial strain was maintained on plates made by adding $1.2 \%(\mathrm{w} / \mathrm{v})$ agar to the liquid medium.

Membrane preparation. Membranes from E. coli ML308 225 in the late-exponential growth phase were prepared and fractionated by sucrose density gradient centrifugation as described previously (Allen \& Scott, 1979). A $500 \mathrm{ml}$ culture of $P$. leiognathi in the late-exponential growth phase was harvested by centrifugation, resuspended in $20 \mathrm{ml}$ deionized water and mixed with $2 \mathrm{mg}$ egg white lysozyme (Sigma) in $20 \mathrm{ml} 30 \mathrm{~mm}$-Tris/ $\mathrm{HCl}$ buffer $\mathrm{pH} \mathrm{7.5.}$ Following incubation at $37^{\circ} \mathrm{C}$ for $15 \mathrm{~min}$, the mixture was centrifuged for $3 \times 10^{4} \mathrm{~g}$-min to remove intact cells and then for $2 \times 10^{6} \mathrm{~g}$-min. The resulting precipitate was resuspended in $2.0 \mathrm{ml} 10 \mathrm{mM}$-HEPES buffer $\mathrm{pH} 7 \cdot 2$ and the membranes were fractionated by sucrose density centrifugation as for $E$. coli ML308 225. Pooled fractions (6 ml) from these gradients were extracted with $50 \mathrm{ml}$ chloroform $/$ methanol $(3: 1, \mathrm{v} / \mathrm{v})$ for $60 \mathrm{~min}$ at room temperature to

+ Present address: Department of Biochemistry, Monash University, Clayton, Victoria, Australia. 
extract phospholipids. The aqueous residues were dialysed against deionized water, freeze-dried and analysed qualitatively for proteins by electrophoresis on $10 \%(\mathrm{w} / \mathrm{v})$ SDS-polyacrylamide gels (Laemmli, 1970).

Bacterial extractions. Outer membrane proteins were also extracted from both species of bacteria using the method described previously (Allen \& Scott, 1979) and were analysed by SDS gel electrophoresis (Laemmli, 1970). Phospholipids and lipopolysaccharides (LPS) were extracted from both species of bacteria and analysed as previously described (Guan \& Scott, 1980), with one exception, as follows: the liquid phase for GLC of fatty acid methyl esters was Silar 9 C P (Allied Science Laboratories Inc., State College, Pa., U.S.A.) on Chromosorb G in a $1.2 \mathrm{~m} \times 6 \mathrm{~mm}$ column, and the temperature programme was $180^{\circ} \mathrm{C}$ for $2 \mathrm{~min}$ after sample injection, followed by heating at $8{ }^{\circ} \mathrm{C} \mathrm{min}^{-1}$ to $240^{\circ} \mathrm{C}$. This regime improved the separation between palmitic and hexadecenoic fatty acid methyl esters.

Analysis of intact phospholipids was carried out on total phospholipid extracts only, using TLC on $20 \times 20 \mathrm{~cm}$ silica gel plates with chloroform/methanol/acetic acid/water $(85: 15: 10: 3$, by vol.) as the solvent. Standard phospholipids were purchased from Sigma. Phospholipids were detected by exposure to iodine vapour.

LPS binding to bacteria. This was measured indirectly, in terms of its effect on the serum bactericidal reaction of $E$. coli ML308 225. Bactericidal assays were carried out as described previously, with and without $P$. leiognathi LPS at a final concentration of $150 \mu \mathrm{g} \mathrm{ml}^{-1}$.

\section{RESULTS AND DISCUSSION}

In an isotonic salts suspension, $P$. leiognathi was not lysed by lysozyme. When resuspended in

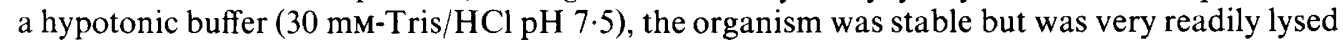
by lysozyme. In this respect, it resembles $E$. coli, in which an osmotic shock is necessary for lysozyme to penetrate the outer membrane before it can hydrolyse the peptidoglycan cell wall (Witholt et al., 1976). Following low speed centrifugation of the $P$. leiognathi lysate, the supernatant was centrifuged at high speed and the resulting precipitate was fractionated by sucrose density gradient centrifugation. As can be seen in Fig. 1, the elution profile of the gradient is almost identical to fractionation of $E$. coli membranes under the same circumstances. The two protein peaks in the $E$. coli elution profile correspond to the outer and cytoplasmic membranes (Schnaitman, 1970; Allen \& Scott, 1979). On this basis, fractions 4-6 were pooled as the outer membranes and fractions 10-12 were pooled as the inner membranes for each gradient elution.

Following extraction with chloroform/methanol, the pooled outer membrane fractions were concentrated and analysed for membrane proteins by SDS gel electrophoresis. These results are presented in Fig. 2. The profile for the $P$. leiognathi outer membrane shows a single major protein with a similar mobility to the characteristic major outer membrane protein complex of E. coli. The remaining proteins are few and present in much smaller quantities. This represents a marked contrast to the $E$. coli outer membrane protein profile, which is more complex. The electrophoretic technique used in these experiments (Laemmli, 1970) resolves the major outer membrane protein complex more effectively that that used previously (Bragg \& Hou, 1972; Allen \& Scott, 1979).

Extraction of a crude particulate fraction from $E$. coli with SDS buffer after a first extraction with a Triton X-100 buffer gives an outer membrane protein preparation which is similar to that obtained from outer membranes purified by sucrose density gradient centrifugation (Schnaitman, 1973; Allen \& Scott, 1979). Similar results are apparent from Fig. 2 in the case of $E$. coli, but the profile for the $P$. leiognathi extract is much more complex than the corresponding profile derived from purified outer membranes. Thus the differential solubility technique which is so convenient for isolating outer membrane proteins from $E$. coli is not suitable for use with $P$. leiognathi.

The chromatographic purification of LPS from $P$. leiognathi was successfully carried out by the same methods as reported for E. coli ML308 225 (Allen \& Scott, 1980). A similar total lipid content (measured as fatty acid methyl esters) of $11 \%$ was found. When added to a mixture of $E$. coli ML308 225 and normal human serum, the LPS from $P$. leiognathi caused a $50 \%$ inhibition of the complement-dependent bactericidal reaction. We have shown previously that this inhibition is due to LPS binding to the bacterial surface, and can also be observed with E. coli K12 (Allen \& Scott, 1980, 1981). The binding of LPS to Salmonella typhimurium outer membranes has also been reported (Jones \& Osborn, 1977). The common feature of LPS which can interact in this 


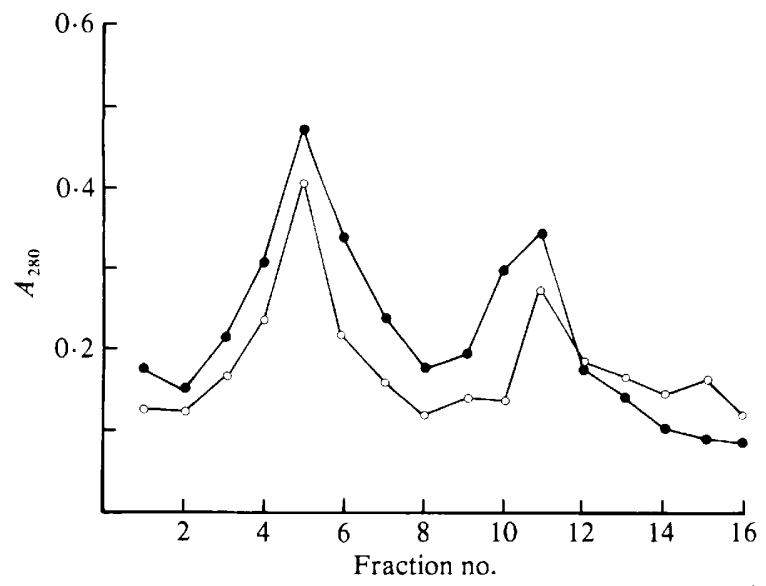

Fig. 1. Sucrose density gradient fractionation of membranes from E. coli ( $\bigcirc)$ and P. leiognathi (O). Bacterial protoplasts were lysed by dilution into cold deionized water and particulate fractions were sedimented by centrifugation for $2000000 \mathrm{~g}$-min. These fractions were layered on to a $35 \mathrm{ml}$ discontinuous sucrose gradient (Schnaitman, 1970) and centrifuged for $77000000 \mathrm{~g}$-min. Fractions $(2 \mathrm{ml} \mathrm{each})$ were collected from the bottom of the tubes and the absorbance at $280 \mathrm{~nm}$ was used as a measure of protein concentration.

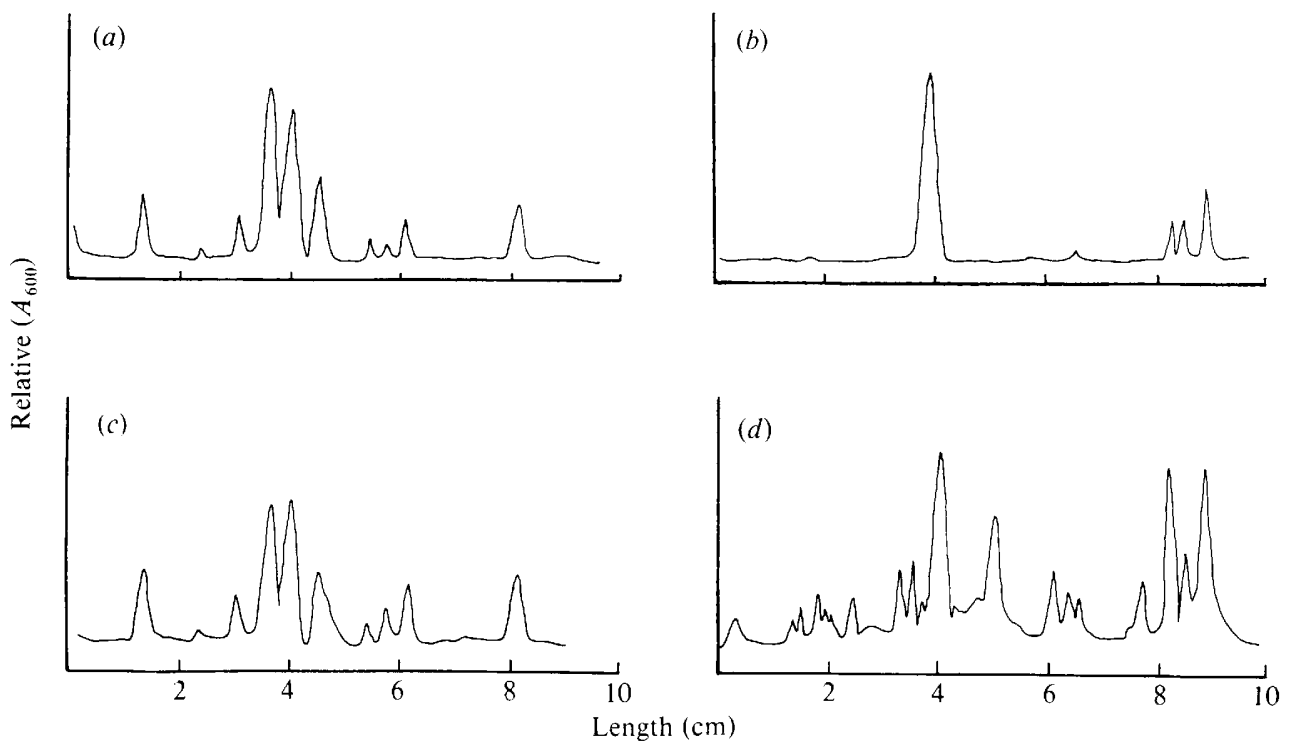

Fig. 2. Electrophoresis on SDS-polyacrylamide gels of outer membrane proteins from $E$. coli and $P$. leiognathi. Outer membrane proteins were extracted from purified outer membranes, or from the particulate fraction of bacterial lysates as described in the text. Polyacrylamide gels $(10 \%, w / v)$ containing SDS were prepared, electrophoresed and stained (Laemmli, 1970), and scanned with an ISCO model 1310 densitometer. The origin of the gel is on the left in each case. (a) Extract of $E$. coli outer membrane. (b) Extract of $P$. leiognathi outer membrane. (c) SDS extract of $E$. coli particulate fraction. (d) SDS extract of $P$. leiognathi particulate fraction.

way with intact bacterial cells is an incomplete outer polysaccharide chain and it has been suggested that this feature minimizes steric interference between the added and the intrinsic LPS (Jones \& Osborn, 1977; Allen \& Scott, 1981). The present result with P. leiognathi LPS suggests that, in this respect, it is similar to the incomplete LPS molecules produced by 'rough' Enterobacteriacae. 
Phospholipid analysis by TLC was qualitative, but phosphatidyl ethanolamine was clearly the predominant phospholipid from both species of bacteria. Phosphatidyl glycerol, phosphatidyl serine and cardiolipin were also detected in smaller quantities in each case. These results are typical of Gram-negative bacteria (Cronan, 1978).

Samples of the total phospholipid and of both membranes from $P$. leiognathi were analysed for fatty acid methyl esters and the results were as follows. The total lipid comprised $26 \%$ palmitic, $57 \%$ hexadecenoic and $17 \%$ octadecenoic acids. In contrast, E. coli comprises $32 \%, 34 \%$ and $25 \%$ of these fatty acids respectively, as well as $2 \%$ myristic and $7 \%$ methylene hexadecenoic acids (Guan \& Scott, 1980). The latter fatty acids were not detected in P. leiognathi. The outer membrane of $P$. leiognathi contained $43 \%$ palmitic, $47 \%$ hexadecenoic and $9 \%$ octadecenoic acids. The cytoplasmic membrane contained $31 \%$ palmitic, $50 \%$ hexadecenoic and $19 \%$ octadecenoic acids. The discrepancy between the total lipid and membrane lipid compositions is at variance with the observed results in E. coli (Koplow \& Goldfine, 1974).

In conclusion, the features of the cell envelope of $P$. leiognathi which have been elucidated in this study are almost entirely typical of terrestrial Gram-negative bacteria, the main exception being the rather simple outer membrane protein composition. There is no evidence at this level of analysis for unusual membrane properties which might account for the ability of the organism to withstand high osmotic pressures. Further information on this ability will probably come from an examination of the dynamic properties of the cytoplasmic membrane. However, the apparent predominance of a single protein species in the outer membrane can possibly be reconciled with the permeability properties of the membrane. Many of the different outer membrane proteins in $E$. coli function in the specific uptake of nutrients from the medium (Di Rienzo et al., 1978). In the apparent absence of a multiplicity of such proteins, it is possible that the single major protein in the outer membrane of $P$. leiognathi forms a single 'pore' of rather broad specificity. This hypothesis would account for the low permeability barrier presented to a variety of small molecules by the outer membrane of this organism.

We wish to thank Mrs R. J. Allen for technical assistance, Miss S. Lamb for helpful discussions, and Mrs M. Smith and Mrs S. Treseder for secretarial assistance.

\section{REFERENCES}

Allen, R. J. \& Scott, G. K. (1979). Biosynthesis and turnover of outer membrane proteins in Escherichia coli ML308 225. Biochemical Journal 182, 407-412.

Allen, R. J. \& ScotT, G. K. (1980). The effect of purified lipopolysaccharide on the bacterial reaction of human serum complement. Journal of General Microbiology 117, 65-72.

AlleN, R. J. \& SCOTT, G. K. (1981). Comparison of the effects of different lipopolysaccharides on the serum bactericidal reactions of two strains of Escherichia coli. Infection and Immunity 31, 831-832.

BaumanN, L. \& BaumanN, P. (1977). Study of relationship among marine and terrestrial enterobacteria by means of in vitro DNA-ribosomal RNA hybridisation. Microbios Letters 3, 11-20.

BraGG, P. D. \& Hou, C. (1972). Organization of proteins in native and reformed outer membrane of Escherichia coli. Biochimica et biophysica acta 274, 478-488.

Cronan, J. E. (1978). Molecular biology of bacterial membrane lipids. Annual Review of Biochemistry 47, 163-189.

Di Rienzo, J. M., Nakamura, K. \& Inouye, M. (1978). The outer membrane proteins of Gramnegative bacteria: biosynthesis, assembly and functions. Annual Review of Biochemistry 47, 481-532.
Guan, L. T. \& ScotT, G. K. (1980). Analysis of outer membrane components of Escherichia coli ML308 225 and of a serum-resistant mutant. Infection and Immunity 28, 387-392.

JONES, N. C. \& OsBoRn, M. J. (1977). Interaction of Salmonella typhimurium with phospholipid vesicles. Incorporation of exogenous lipids into intact cells. Journal of Biological Chemistry 252, 73987404.

Koplow, J. \& Goldfine, H. (1974). Alterations in the outer membrane of the cell envelope of heptosedeficient mutants of Escherichia coli. Journal of Bacteriology 117, 527-543.

LAEMMLI, U. K. (1970). Cleavage of structural proteins during the assembly of the head of bacteriophage T4. Nature, London 227, 680-685.

Nealson, K. H. \& Hastings, J. W. (1977). Low oxygen is optimal for luciferase synthesis in some bacteria: ecological implications. Archives of Microbiology 112 , 9-16.

Nealson, K. H. \& Hastings, J. W. (1979). Bacterial bioluminescence: its control and ecological significance. Microbiological Reviews 43, 496-518.

Reichelt, J. L. \& Baumann, P. (1973). Taxonomy of the marine, luminous bacteria. Archiv für Mikrobiologie 94, 283-330. 
Richmond, M. H. \& Sykes, R. B. (1973). The $\beta$ lactamases of Gram-negative bacteria and their possible physiological role. Advances in Microbial Physiology 9, 31-88.

Schnaitman, C. A. (1970). Examination of the protein composition of the cell envelope of Escherichia coli by polyacrylamide gel electrophoresis. Journal of Bacteriology 104, 882-889.
Schnaitman, C. A. (1973). Outer membrane proteins of Escherichia coli. II. Heterogeneity of major outer membrane polypeptides. Archives of Biochemistry and Biophysics 157, 553-560.

Witholt, B., van Heerikhuisen, H. \& de LeiJ, L. (1976). How does lysozyme penetrate through the bacterial outer membrane? Biochemica et biophysica acta 443, 534-544. 